\title{
HEURISTIC POTENTIAL OF LUHMANN'S THEORY OF AUTOPOIESIS IN SOCIAL NETWORKS
}

\author{
Hanna Sukharevska \\ Candidate of Sciences in Social Communication, \\ Senior Lecturer at the Department of Journalism and Ukrainian Studies, \\ National University of Water and Environmental Engineering, Ukraine \\ e-mail: info.sann@gmail.com,orcid.org/0000-0001-8938-7915
}

\begin{abstract}
Summary
The beginning of the study of computer discourse was determined in the traditional categorical-instrumental set, therefore, a methodological leap is needed to enter a new round of understanding the situation. Appealing to interdisciplinary research makes it possible to involve the conceptual apparatus of mathematical and non-classical information theories and theories of complex systems. In our opinion, powerful heuristic potential has the concept of autopoiesisby N. Luhmann, which was, in turn, rethought by Humberto Maturana and Francisco Varela. According to the mentioned researchers, the Internet is a self-organizing system that creates a description of itself, and every communication that takes place in it also creates a self-description. According to the theory of systems by N. Luhmann, the structures of the system, which are built from its own operations, are organized in a similar way. The concept of autopoiesis made it possible to understand and study the dynamic structure of network communities, and this has also allowed to reconsider the perception of communication in the network which is fundamentally different from communication in reality. Processes of self-organization of network communities and the functioning of social networks in this context is an absolutely unique phenomenon that leads social development and humanity, however, it hides certain risks and shortcomings that are still insufficiently explored and need in-depth analysis. In particular, these are the laws of functioning of networks and factors of their self-reproduction.
\end{abstract}

Keywords: autopoiesis, Internet system, self - organization of communications.

DOI: https://doi.org/10.23856/4426

\section{Introduction}

The definition of the World Wide Web as a new communication space has long been a proven fact that is not disputed. However, the methodological contradiction of modern science is that the new virtual reality is described with the "outdated" categories. In a certain sense, this is a conflict between method and object. The beginning of the study of computer discourse was defined in the traditional categorical-instrumental set, that's why a methodological leap is needed to enter a new round of understanding of new phenomena. Reality is changing, destroying all existing traditional ideas, contemporaneously transforming the ideas in the phenomenological aspect as well as epistemological preconditions. Thus, we can't agree more with E. Lavrenchuk that "for studying new discursive practice we need a new conceptual and terminological apparatus, which is an adaptation of old conceptual and terminological paradigm regarding the new object of study, constructed in such a way that the nature of this object and the apparatus applied for its description are correlated with each other. In defining the conceptual and categorical apparatus, foremost we describe the constructive features of virtual 
discourse that are the most important for us" (Lavrenchuk, 2011:6). Fully sharing this view, we believe that science nowadays should not be limited to the statement of factual material about the existence of communication, but should develop a special methodological basis for its further analysis. Same as the study of the social manifestations of the Internet should not be limited to the projection of a functionalist approach, forming outdated clichés from the concepts of real society.

In this sense, the theory of communication should be open to knowledge of related disciplines, it should be possible to rethink the developments in other sciences. The appeal to interdisciplinary research that gives opportunity to involve the conceptual apparatus of non-classical communicative theories, concepts of complex systems and synergetic principles, has a powerful heuristic potential. Such an interpretation allows us to find new significant meanings for progressing in the opposite direction.

In this context, the study of the realities of the Internet reality should involve the texts of modern researchers of the technogenic world, such as N. Luhmann, E. Pickering, K. Knorr-Cetina, B. Latour, M. Castells, L. Memford, W. Galston, who are the classics of rethinking the nature of technosocial phenomena similar to Internet networks. Thus, B. Latour mentioned "ontological turn" in research, he claims that this topic will answer the question what society is made of. (Latour, 2003). K. Knorr-Cetina develops approaches in the field of "post-social research" (Knorr-Cetina). Actor-network theory in this sense allows us to rethink the impact of technology on a person and his communication.

Even greater heuristic potential, in our opinion, has the concept of autopoiesis by N. Luhmann, which in turn was rethought by W. Maturana and F. Varel. Thus, in "Autopoiesis of Social Systems", N. Luhmann writes that the essence of communication, which is recursively produced and reproduced by the communicative network cannot exist outside it (Luhmann, 1990:54). Let's take a look at his theory in more detail.

\section{The main part}

Computer networks, video production of computer networks, design of microelectronics based on nanotechnology, agriculture based on modern biotechnology etc. as well as many other industries are the examples of the invasion of technogenic factors in our lives.

U. Maturana and F. Varela in the 1970s substantiated the concept in which it's claimed that the tool that transforms systems into autonomous units is manifested through autopoiesis: "The system is autonomous," they write, "if it establishes its own relevant laws. Autonomy is one of the most significant features of living beings ... now we imagine what defines living beings as unities - it is their autopoietic organization" (Maturana, Varela, 1976). They position the actors - users of the network, as tools of communication processes that support autopoiesis. Due to this, autopoiesis appears as a system that reproduces all its elementary parts on its own, with the help of an existing network of the same elements and thus separates itself from the external environment (Luhmann, 2005). This can happen in the form of life, in the form of consciousness or, in the case of a social system - in the form of communication.

In this sense, autopoiesis can be considered as a way to reproduce the system through itself (Lavrenchuk, 2011). Autopoietic architectonics is unique as its structural organization determines products themselves as a product, without division into manufacturer and product. Neurobiologists W. Maturana and F. Varela used the concept of "autopoietic machine" in describing the key property of a living system, its continuous regeneration and maintenance of its own identity (Maturana, Varela, 1976). 
In this context, it is important to note that the development of microsocial communities, with all the diversity of their functioning, is subject to the laws of development of large social groups of cyberspace. Whereas the function of form can be performed only by such factors that have the property to create certain dependencies under the influence of which the meaningful processes can develop. And the boundaries of the social system of virtual network communities create this area.

Thus, social networks, which autopoietically constitute themselves by distinguishing between medium and form, create differentiations that generate communication. Accordingly, the autopoietic nature of social networks is expressed in the fact that these systems themselves are able to establish and change their elements through relational processes and reproduction of social networks is not a repetition of a previously existing organization, but the constant reproduction of new elements associated with existing ones.

As social network researcher E. Lavrenchuk writes, "the mechanistic comparison of different communities or technological solutions are used by these communities to implement communication processes and it cannot give a real picture of social relations in virtual network communities, because these communities don't just coexist and use certain technologies but are intertwined with lots of social connections. Cyberspace itself is transformed: new information resources appear and old ones disappear, accordingly, virtual network communities appear and cease to exist, information flows change their direction, new algorithms and techniques of information processing and transmission are created" (Lavrenchuk, 2011:34).

In social networks, each communication that is generated is followed by another non-identical communication, but it corresponds to the general communicative code of the system, its content and is always defined in advance, before the communication takes place. We agree that a system that has only one repetitive communication would lose its meaning: it would cease to be a system due to its lack of complexity. That is why, in our opinion, their autopoiesis does not presuppose the reproducibility of any specific (predetermined) reasons and conditions for the constitution of systems.

In this context, it is important to mention that all researchers of the Web in connection with the constant development of the Internet note the factor of formation of new types and algorithms of communicative behavior. Almost unanimously, they note the fact that the Web is mostly dominated by horizontal links and there are no time limits as well as territorial and hierarchical boundaries. On the Internet, the conditions that are necessary for communication can be reproduced without any reference to hierarchical "top". This is primarily due to the fact that the development of social structures in the Network includes the ability to restructure the hierarchy of communication depending on the increasing interest of the user. This interest is growing in unpredictable media space, which is constantly expanding. The possibilities of operating information in such a system are not only free of censorship, as noted, but they are practically unrestricted, except the users' ability to dispose of their own freedom. In the same row there are new conditions for the accumulation and evaluation of information; possibility to separate the processes of communication and perception; erasure of almost all spatial, status and property restrictions within the communication, etc.

Possession of information, ultimately turns into knowledge, not property, becomes a determining factor in social differentiation. The division into "rich" and "poor" acquires a fundamentally new character: the privileged layer andnew "poor" uninformed layer. The center of social conflicts is moving from the economic sphere to the sphere of culture. The result of the struggle and resolution of conflicts is the development of new and fading of old social institutions. "Intelligent" technology becomes an infrastructure of the information society. It 
is gradually replacing the old technology - "mechanical". Social organization and information technology form a "symbiosis". And with this fact society enters the "technotronic era".

Thus, the communications that take place in the Web have the necessary complexity endless options for their extensions. However, the Internet, as a system that has established closed relationship with the environment, organizes the reduction through its mechanisms, reducing complexity to the possibilities that ensure its functioning. (Lavrenchuk, 2011).

In particular, this mechanism is a double contingent, which, on the one side, demonstrates "dependence on" (contingenton), i.e. produces the orientation of communications to a common communicative code, on the other side, it retains the possibility of genesis of the other, as a signifier of denial of impossibility and conditioned necessity. In turn, the user chooses, on the one hand, the operation (communication) that is adjacent to the past operations (communications), on the other hand, he discovers in himself and through himself on the Internet some new virtual spaces, worlds. To analyze the Internet as an environment that generates a unique communication culture, it is necessary to identify the fundamentals, a kind of distinction on which this structure is built, namely: information databases, communication systems and search engines.

That's why social networks act not only as self-referential, but also as autopoietic systems. To analyze the Internet as an environment that generates a unique communicative culture, it is necessary to identify the fundamentals, a kind of distinction on which this structure is built, namely: information databases, communication systems and search engines (Lavrenchuk, 2011). Social networks, being structural elements of the Internet, include components of all three denominated bases. In turn, the communication component of social networks is defined by E. Lavrenchuk as the main one, because historically electronic networks have developed from communication platforms that reproduce human connections with the help of computer technology.

Arguing the latter statement, he emphasizes that the development of network Internet structures is similar in type to the behavior of open systems described in synergetics, where except system openness there are two more features - nonlinearity of the system and its distance from equilibrium. Thus, such communications are autopoietic, i.e. self-reproducing (Lavrenchuk, 2011). Each communication generates information, which in turn generates new communications. Accordingly, the network as a whole generates itself, so it is autopoietic. Repeated through a multitude of feedbacks, communications generate a common system of beliefs, explanations, and valuesthat is supported by subsequent communications. Through such a general information context, the subjects express their identities -suchwise the network builds its own boundaries. But this is not a physical boundary, like a cell membrane, but a completely different one, which determines the specifics of the diffusion of information. Thus, the process of communication itself is of paramount importance for the system, as it is the basis of its distinction from the external environment. Thus, the operability of information on the Internet dominates over causality (Lavrenchuk, 2011). It should be mentioned that this behavior of the system was described by J.-F. Lyotard in The State of Postmodernism.J.-F. Lyotard stated that legitimacy is formalized through productivity: "Productivity is self-legitimizing, as is apparently the case with a system that is adjusted to optimize its results". (Lyotard, 2011).

\section{Conclusion}

The Internet is a set of communications organized through data transmission. The Internet uses its own descriptions to determine the status of operations, which, in turn, are the basis 
for further operations. Thus, at present, productivity growth and its self-legitimation go through the production, storage, availability and operability of information. Based on the above, we can define the Internet as an operationally closed structure that has the accumulative property of completely different systems (social and technological), has its own border, as well as an autopoietic device that starts the process of self-reproduction. In this sense, autopoiesis is an important concept, in our view, as it allows us to identify the essential properties of the growing Internet space. The process of autopoiesis is manifested not only in self-reproduction, but also in separation from the environment. Systems with autopoietic organization reproduce themselves. Speaking of the latter and summarizing our analysis, it should be noted that cyberculture operates on the principle of autopoiesis, which finds expression as a rhizome, as hypertext. These multiple layers make cyberculture unique, and communication processes in it specific.

\section{References}

Latur, B. (2003), Kogda veshchi daiut sdachi: vozmozhnyi vklad "issledovanii nauki" v obshchestvennye nauki [When things fight back: the possible contribution of "science research" to social sciences], Vestnik MGU, vol. 3, p. 33. [in Russian]

Lavrenchuk, E. A. (2011), Autopoiezissotcialnykhsetei v internet-prostranstve [Autopoiesis of social networks in the Internet space], PhD diss. (philosoph. sci.), Moscow, Russian State University for the Humanities (RGGU), 186 p. [in Russian]

Luhmann, N. (1993), Grundrisse der allgemeiner Sozialtheorie, Munchen, Beck-Verlag.

Luhmann, N. (2007), Sotcialnye sistemy: Ocherk obshchei teorii. [Social systems: an outline of general theory], St. Petersburg, Nauka, 648 p. [in Russian]

Lyotard,J.-F. (1998), Sostoianie postmoderna. [The state of postmodern], SPb., p. 80. [in Russian]

Maturana, U., Varela F. (2001), Drevo poznaniia [Tree of knowledge], translated by Danilova, Iu.A., M., Progress-Traditciia. [in Russian] 